\title{
Glycosylation in the near-term epitheliochorial placenta of the horse, donkey and camel: a comparative study of interbreeding and non-interbreeding species
}

\author{
C. J. P. Jones ${ }^{1}$, F. B. P. Wooding ${ }^{2}$, M. M. Abd-Elnaeim ${ }^{3}$, R. Leiser ${ }^{4}$, V. Dantzer ${ }^{5}$ \\ and R. W. Stoddart ${ }^{6}$ \\ ${ }^{1}$ Academic Unit of Obstetrics and Gynaecology, School of Medicine, University of Manchester, St Mary's Hospital, Whitworth Park,

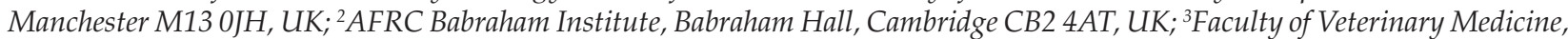 \\ University of Assiut, Assiut, Egypt; ${ }^{4}$ Institute for Veterinary Anatomy, Histology and Embryology, University of Giessen, \\ D-35392 Giessen, Germany; ${ }^{5}$ Institute of Anatomy and Physiology, Royal Veterinary and Agricultural University, \\ DK-1870 Frederiksberg C, Denmark; and ' ${ }^{6}$ chool of Medicine, Faculty of Medicine, Dentistry and Nursing, University of Manchester, \\ Oxford Road, Manchester M13 9PT, UK
}

\begin{abstract}
Studies from this laboratory have shown great diversity in the glycosylation of tissues comprising the interhaemal barrier of species with different placental types. This diversity may be one of the factors preventing interbreeding between species. Glycan expression within the uterine epithelium and trophoblast of the interhaemal barrier was examined to test this proposition in three species with similar diffuse, microcotyledonary, epitheliochorial allantochorionic types of placenta: the horse (Equus caballus) and donkey (Equus asinus), which can interbreed with each other, and the camel (Camelus dromedarius), which cannot interbreed with either of the other two species. A panel of 14 lectins was used and it was found that glycosylation patterns were generally similar between placental tissues of the horse and donkey, except for the expression of non-bisected complex $\mathrm{N}$-glycan and some sialic acids, whereas those of the camel showed striking differences in the binding of lectins to many structures carrying terminal residues of fucose, $N$-acetyl galactosamine and $\beta$-galactose, as well as to complex $\mathrm{N}$-glycans and sialic acids. These results are consistent with the proposition that interbreeding species carry similar glycans in tissues forming the interhaemal barrier whereas glycodiversity is one of the factors preventing implantation and subsequent placental development in interspecific hybrids.
\end{abstract}

\section{Introduction}

Glycan expression in the tissue layers comprising the interhaemal barrier has been shown to vary in different placental types (Jones et al., 1997a) and this may be one of the factors preventing interbreeding between species. Glycosylation patterns of the maternal epithelium and microcotyledonary trophoblast of three species possessing epitheliochorial placentation were studied to examine this proposition. Two of the species studied (horse and donkey, Equidae) can interbreed, while the third species, the camel (Camelidae), cannot interbreed with either of the other two species. The placentae of horses and donkeys are structurally very similar, being diffuse, microcotyledonary and villous (Allen, 1982; Steven, 1982; Leiser and Kaufmann, 1994; Wooding and Flint, 1994; Allen and Short, 1997) while the camel placenta is also diffuse and microcotyledonary, but the degree of villous branching is much less pronounced, producing rather squat, knob-like villi, especially in early pregnancy (Van Lennep, 1961, 1963; Abd-Elnaeim, 1998;
Leiser et al., 1998). The camel placenta also differs from that of the horse and donkey in having occasional giant cells in the trophoblast (Van Lennep, 1961, 1963; Skidmore et al., 1996; Abd-Elnaeim et al., 1999).

In epitheliochorial placentation, there is close interdigitation of the apposed microvilli covering the luminal surface of the maternal uterine epithelium and the fetal trophoblast (Björkman, 1970). The initial association of the apical surface of the cells of the trophoblast with the uterine epithelium is somewhat irregular in the horse (Enders and Liu, 1991); the trophoblast cells have long microvilli whereas the uterine epithelial cells are stubby, and interdigitation is absent initially, although it is established by day 46 of gestation (Samuel et al., 1976). In camels, the process of attachment is more gradual and complex (Skidmore et al., 1996; Abd-Elnaeim et al., 1999), with variation in the type of intercellular adhesion, ranging from the meeting of trophoblastic microvilli with flat uterine ectoplasmic pads to full interdigitation of trophoblastic and uterine microvilli separated by a gap of only about $20 \mathrm{~nm}$. As these microvilli are heavily glycosylated (Jones et al., 1997a), 
their intercellular contact is probably mediated via glycanglycan interactions (Aplin, 1997).

Evolutionary divergence of the phylogenetic groups containing horses (Perissodactyla) and camels (Artiodactyla) is estimated to have occurred 60-80 million years ago (Miyamoto et al., 1993; Kumar and Hedges, 1998) while the genus Equus invaded the Old World no more than 2.5 million years ago, so that divergence of horses and donkeys can be no older than this (Churcher and Richardson, 1978). Hence, the opportunity for molecular evolution and mutation of placental glycans is considerable between horses and camels and minimal between horses and donkeys. The present study is an examination of the materno-fetal interface of the horse, donkey and camel near-term epitheliochorial placenta and a comparison of the glycans expressed therein.

\section{Materials and Methods}

Near-term placentae from a horse (Equus caballus, $80 \mathrm{~cm}$ crown-rump (C-R) length), donkey (Equus asinus, $80 \mathrm{~cm} \mathrm{C-R}$ length) and camel (Camelus dromedarius, $100 \mathrm{~cm} \mathrm{C-R} \mathrm{length)}$ were perfuse-fixed and diced into full-depth pieces. The horse placenta, from the TBA Equine Fertility Unit (Newmarket, UK) via the Babraham Institute (Cambridge, UK), was perfusion-fixed from both fetal and maternal sides with 3\% $(\mathrm{w} / \mathrm{v})$ paraformaldehyde-1\% (v/v) glutaraldehyde and embedded in Araldite epoxy resin. The camel placenta was obtained from the abattoir at Cairo (Egypt) whereas the donkey placenta was given by the Assiut Veterinary Hospital (Egypt). Both placentae were available within 15 min of the death of the animal and fixed by perfusion with $3 \%(\mathrm{v} / \mathrm{v})$ glutaraldehyde in 0.1 mol phosphate buffer $1^{-1}, \mathrm{pH} 7.3$, with $2 \%(\mathrm{w} / \mathrm{v})$ polyvinylpyrrolidone through a small branch of the uterine artery on the maternal side and a small branch of the umbilical artery on the fetal side. The placentae were then immersion fixed for $2 \mathrm{~h}$ in the same fixative. After washing in buffer, full depth slices of placental tissue were dehydrated in an ascending alcohol series, treated with propylene oxide and infiltrated with Taab epoxy resin (Taab Laboratories Equipment Ltd, Aldermaston) before being embedded in flat-bottomed capsules and polymerized at $60^{\circ} \mathrm{C}$ for $72 \mathrm{~h}$. Sections $1.5 \mu \mathrm{m}$ thick were cut from selected areas of all three specimens, mounted on 3-aminopropyltriethoxysilane (APES)-coated slides and stained with a panel of 14 biotinylated lectins and an avidin-peroxidase revealing system as described by Jones et al. (1999). Resin was removed with saturated sodium ethoxide diluted 1:1 with absolute ethanol for $15 \mathrm{~min}$ and, after washing in ethanol and then in distilled water, endogenous peroxidase was blocked with $10 \%$ $(\mathrm{v} / \mathrm{v})$ hydrogen peroxide $(\mathrm{BDH}$, Poole) before exposure to $0.03 \%(w / v)$ trypsin (Type II crude, Sigma) in 0.05 mol Tris-

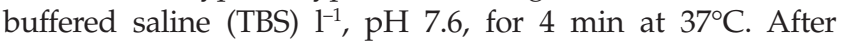
washing, sections were incubated with $10 \mu \mathrm{g}$ biotinylated lectin $\mathrm{ml}^{-1}$ (Sigma; SNA and MAA from Boehringer Mannheim, Lewes; LFA from EY Laboratories, San Mateo, CA; see Table 1 for the major sugar specificities of the lectins) in $0.05 \mathrm{~mol} \mathrm{TBS}^{-1}$ containing $1 \mathrm{mmol}$ calcium chloride $1^{-1}$ for $1 \mathrm{~h}$ at $37^{\circ} \mathrm{C}$, washed in the same buffer then treated with $5 \mu \mathrm{g}$ avidin peroxidase $\mathrm{ml}^{-1}$
(Sigma) in 0.125 mol TBS ${ }^{-1}, \mathrm{pH} 7.6$, with 0.347 mol sodium chloride $1^{-1}$ for $1 \mathrm{~h}$ at $37^{\circ} \mathrm{C}$ (Jones et al., 1987). Sections were washed and sites of lectin binding revealed with $0.05 \%(\mathrm{w} / \mathrm{v})$ diaminobenzidine tetrahydrochloride dihydrate (Aldrich

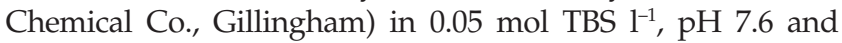
$0.015 \%(\mathrm{v} / \mathrm{v})$ hydrogen peroxide (30 volumes) for $5 \mathrm{~min}$ at $18 \pm$ $0.5^{\circ} \mathrm{C}$. Sections were rinsed, air-dried and mounted in neutral synthetic mounting medium $(\mathrm{BDH})$. Controls were carried out as described by Jones et al. (1997a,b). Sections were assessed using a ranking system of analysis whereby staining intensity was allocated a grade from 0 (negative) to 4 (intensely stained) and intracellular granule density was allocated a grade from + (sparse) to ++++ (densely packed). Inter- and intra-observer error was tested to assess the reproducibility of the system.

Owing to the great difficulty in obtaining carefully dated and perfuse-fixed specimens for this study, only one placenta from each species was studied. The problem of obtaining material from large species such as these has been addressed by Jones et al. (1999). The main limiting factor in the present study was that access to suitable donkey material was severely limited, with only two specimens available to date, one of which was near-term. Therefore, the horse and camel placentae were selected to match as closely as possible to the gestational age of the donkey.

\section{Results}

\section{Maternal uterine epithelium}

PSA bound more strongly to camel uterine epithelium than to that of horse or donkey, while e-PHA showed only weak, diffuse staining of the camel tissue compared with moderate to strong staining of both horse and donkey epithelia (Fig. 1a-c). L-PHA (Fig. 1d-f) was bound by a subpopulation of epithelial granules in the horse only. MPA, SBA, ECA and WFA bound well to all three epithelia, while staining with AHA was strongest in the camel and weakest in the donkey epithelia (Fig. 1g-i). There was no detectable binding of DBA to the camel tissue, but strong to intense staining of donkey and horse epithelia (Fig. 2a-c). In contrast, LTA (Fig. 2d-f) and UEA-1 both bound to camel epithelium, whereas the epithelia of horse and donkey gave no staining with LTA, and weaker staining with UEA-1. No staining with SNA was observed in any of the species and MAA stained only occasional granules in the donkey epithelium. LFA bound to subpopulations of intracellular granules in horse and donkey epithelia but no staining was observed in that of the camel (Fig. $2 g-i$ ).

\section{Microcotyledonary trophoblast}

All three species showed some degree of binding of PSA and e-PHA (Fig.1a-c), but this was weakest in the camel tissues, which also showed diffuse staining with e-PHA and nuclear staining within the trophoblast cells (Fig. 1a). However, 1-PHA did not stain the camel trophoblast but, in both horse and donkey trophoblast, it was strongly bound (Fig. 1d-f). Both AHA and ECA bound more to horse and 
Table 1. Lectins used in this study and their major specificities

\begin{tabular}{|c|c|c|c|}
\hline Acronym & Source & Major specificity & Reference \\
\hline PSA & $\begin{array}{l}\text { Pisum sativum } \\
\text { (garden pea) }\end{array}$ & $\begin{array}{l}\alpha-D-m a n n o s e ~ i n ~ n o n-b i s e c t e d ~ b i / t r i-a n t e n n a r y, \\
\text { complex } N \text {-linked sequences }\end{array}$ & $\begin{array}{l}\text { Trowbridge, 1974; } \\
\text { Debray et al., } 1981\end{array}$ \\
\hline e-PHA & $\begin{array}{l}\text { Phaseolus vulgaris } \\
\text { (kidney bean) } \\
\text { (erythroagglutinin) }\end{array}$ & $\begin{array}{l}\text { Bi/tri-antennary bisected complex } N \text {-linked } \\
\text { sequences }\end{array}$ & $\begin{array}{l}\text { Cummings and Kornfeld, 1982; } \\
\text { Yamashita et al., } 1983\end{array}$ \\
\hline 1-PHA & $\begin{array}{l}\text { Phaseolus vulgaris } \\
\text { (kidney bean) } \\
\text { (leukoagglutinin) }\end{array}$ & $\begin{array}{l}\text { Tri/tetra-antennary, non- bisected complex } \\
N \text {-linked sequences }\end{array}$ & $\begin{array}{l}\text { Hammarström et al., 1982; } \\
\text { Green and Baenziger, } 1987\end{array}$ \\
\hline AHA & $\begin{array}{l}\text { Arachis hypogaea } \\
\text { (peanut) }\end{array}$ & Gal $\beta 1,3$ GlcNAc $\beta 1->$ Gal $\beta 1,4$ GlcNAc $\beta 1-$ & $\begin{array}{l}\text { Lotan and Sharon, 1978; } \\
\text { Sueyoshi } \text { et al., } 1988\end{array}$ \\
\hline ECA & $\begin{array}{l}\text { Erythrina cristagalli } \\
\quad \text { (coral tree) }\end{array}$ & Gal $\beta 1,4$ GlcNAc $\beta 1-$ & $\begin{array}{l}\text { Iglesias et al., 1982; } \\
\text { De Boeck et al., } 1984\end{array}$ \\
\hline MPA & $\begin{array}{l}\text { Maclura pomifera } \\
\text { (osage orange) }\end{array}$ & Gal $\beta 1,3$ GalNAc $\alpha 1->$ GalNAc $\alpha 1-$ & Sarkar et al., 1981 \\
\hline SBA & $\begin{array}{l}\text { Glycine max } \\
\text { (soybean) }\end{array}$ & Terminal GalNAc $\alpha 1->$ Gal $\alpha 1$ & $\begin{array}{l}\text { Pereira et al., 1974; } \\
\text { Bhattacharyya et al., } 1988\end{array}$ \\
\hline WFA & $\begin{array}{l}\text { Wisteria floribunda } \\
\quad \text { (wisteria) }\end{array}$ & GalNAc $\alpha 1,6 \mathrm{Gal} \beta 1->$ GalNAc $\alpha 1,3 \mathrm{Gal} \beta 1-$ & $\begin{array}{l}\text { Sugii and Kabat, 1980; } \\
\text { Baker et al., } 1983\end{array}$ \\
\hline DBA & $\begin{array}{l}\text { Dolichos biflorus } \\
\text { (horse gram) }\end{array}$ & GalNAc $\alpha 1,3(\mathrm{~L}-\mathrm{Fuc} \alpha 1,2) \mathrm{Gal}-\beta 1,3 / 4 \mathrm{GlcNAc} \beta 1-$ & $\begin{array}{l}\text { Etzler and Kabat, 1970; } \\
\text { Baker et al., } 1983\end{array}$ \\
\hline UEA-1 & $\begin{array}{l}\text { Ulex europaeus-1 } \\
\quad \text { (gorse) }\end{array}$ & L-Fuc $\alpha 1,2$ Gal $\beta 1,4-G l c N A c \beta 1-$ & $\begin{array}{l}\text { Hindsgaul et al., } 1985 \\
\text { Debray et al., } 1981\end{array}$ \\
\hline LTA & $\begin{array}{l}\text { Tetragonolobus purpureus } \\
\text { (lotus) }\end{array}$ & $\alpha$-L-fucosyl termini (especially where clustered) & $\begin{array}{l}\text { Pereira and Kabat, 1974; } \\
\text { Debray et al., } 1981\end{array}$ \\
\hline SNA & $\begin{array}{l}\text { Sambucus nigra } \\
\text { (elderberry bark) }\end{array}$ & NeuNAc $\alpha 2,6 \mathrm{Gal} / \mathrm{GalNAc-}$ & Shibuya et al., 1987 \\
\hline MAA & Maackia amurensis & NeuNAc $\alpha 2,3$ Gal $\beta 1-$ & $\begin{array}{l}\text { Wang and Cummings, 1988; } \\
\text { Knibbs et al., } 1991\end{array}$ \\
\hline LFA & $\begin{array}{l}\text { Limax flavus } \\
\text { (yellow slug) }\end{array}$ & Certain sialyl termini & $\begin{array}{l}\text { Miller et al., 1982; } \\
\text { Knibbs et al., } 1993\end{array}$ \\
\hline
\end{tabular}

donkey trophoblast than to camel trophoblast (Fig. 1g-i), while SBA showed a converse pattern, staining only a subpopulation of granules in the camel cells. DBA did not stain the camel trophoblast, but occasional granules were evident in horse and donkey trophoblast (Fig. 2a-c), whereas neither LTA (Fig. 2d-f) nor UEA-1 bound to horse or donkey trophoblast, although a subpopulation of intracellular granules was stained in the camel. MPA and WFA showed little difference in staining among the three species, with MPA staining moderately to strongly and WFA more intensely. SNA and MAA failed to bind to the trophoblast in all three species and there was only weak staining of occasional intracellular granules by LFA in horse trophoblast (Fig. 2h).

\section{Interdigitating microvillous membrane}

In the horse placenta, the presence of granules in either the maternal or fetal compartment was matched by staining of the interdigitating microvillous membrane. Those lectins that bound moderately or weakly to the membrane included
PSA, ePHA (Fig. 1b), 1-PHA (Fig. 1e), UEA-1, MPA and WFA, while LTA (Fig. 2e), SNA and MAA showed no staining. The other lectins (AHA (Fig. 1h), DBA (Fig. 2b), ECA, SBA and LFA (Fig. 2h)) bound strongly. The pattern of binding in donkey placenta was similar except that staining with UEA-1 was absent and AHA and LFA showed only moderate binding (Figs 1i and 2i). All the other lectins exhibited strong to intense staining of the microvillous membrane. The camel placenta differed markedly in the lectin binding pattern of this membrane. L-PHA, DBA (Figs 1d and 2a), SNA, MAA and LFA (Fig. 2g) did not bind, while e-PHA (Fig. 1a), UEA-1, AHA (Fig. 1g) and ECA showed weak to moderate staining. All the other lectins (PSA, LTA (Fig. 2d), MPA, SBA, and WFA) bound strongly or intensely. These results have been summarized graphically (Fig. 3).

\section{Controls}

Substitution of the buffer for the lectin resulted in complete absence of stain, while incubation of the tissue with lectin in 

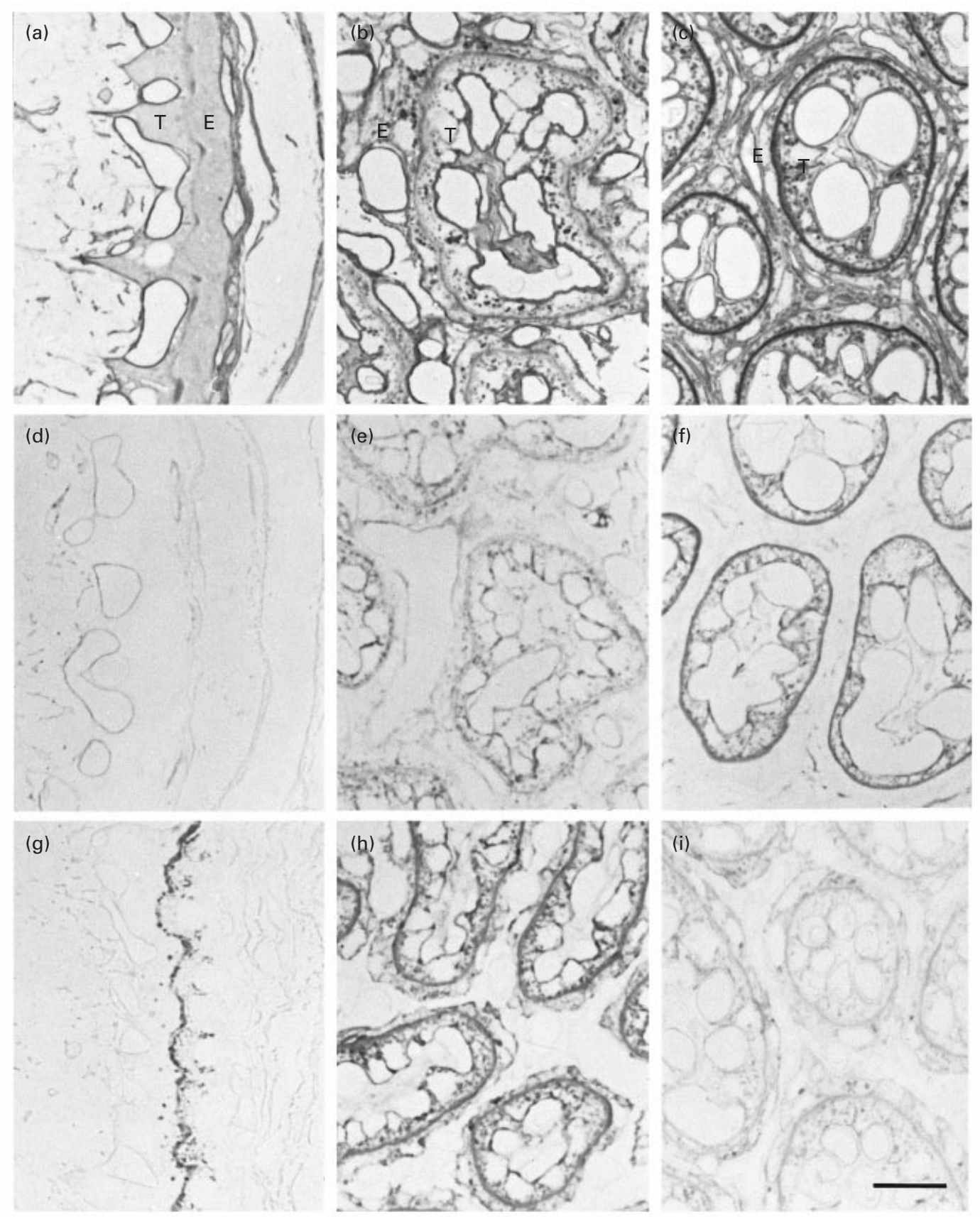

Fig. 1. (a-c) Phaseolus vulgaris erythroagglutinin (e-PHA) binding to camel (a) is weak and diffuse while moderate to strong in horse (b) and donkey (c). (d-f) Phaseolus vulgaris leukoagglutinin (l-PHA) binding to camel (d), horse (e) and donkey (f), with absence of staining in the camel and donkey uterine epithelia and in the camel trophoblast. (g-i) Arachis hypogaea agglutinin (AHA) binds to subpopulations of granule in camel (g), horse (h) and donkey (i) epithelia and trophoblast. E, maternal uterine epithelium; T, trophoblast. Scale bar represents $20 \mu \mathrm{m}$.

the presence of its competing sugar resulted in a marked reduction or elimination of staining, as described by Jones et al. (1997a,b, 1999). Testing of inter- and intraobserver error showed a very high degree of consistency in assessing the degree of staining within tissues.

\section{Discussion}

The lectin-binding patterns of horse and donkey uterine epithelium and trophoblast show a striking resemblance, implying close similarities between their glycans, while 

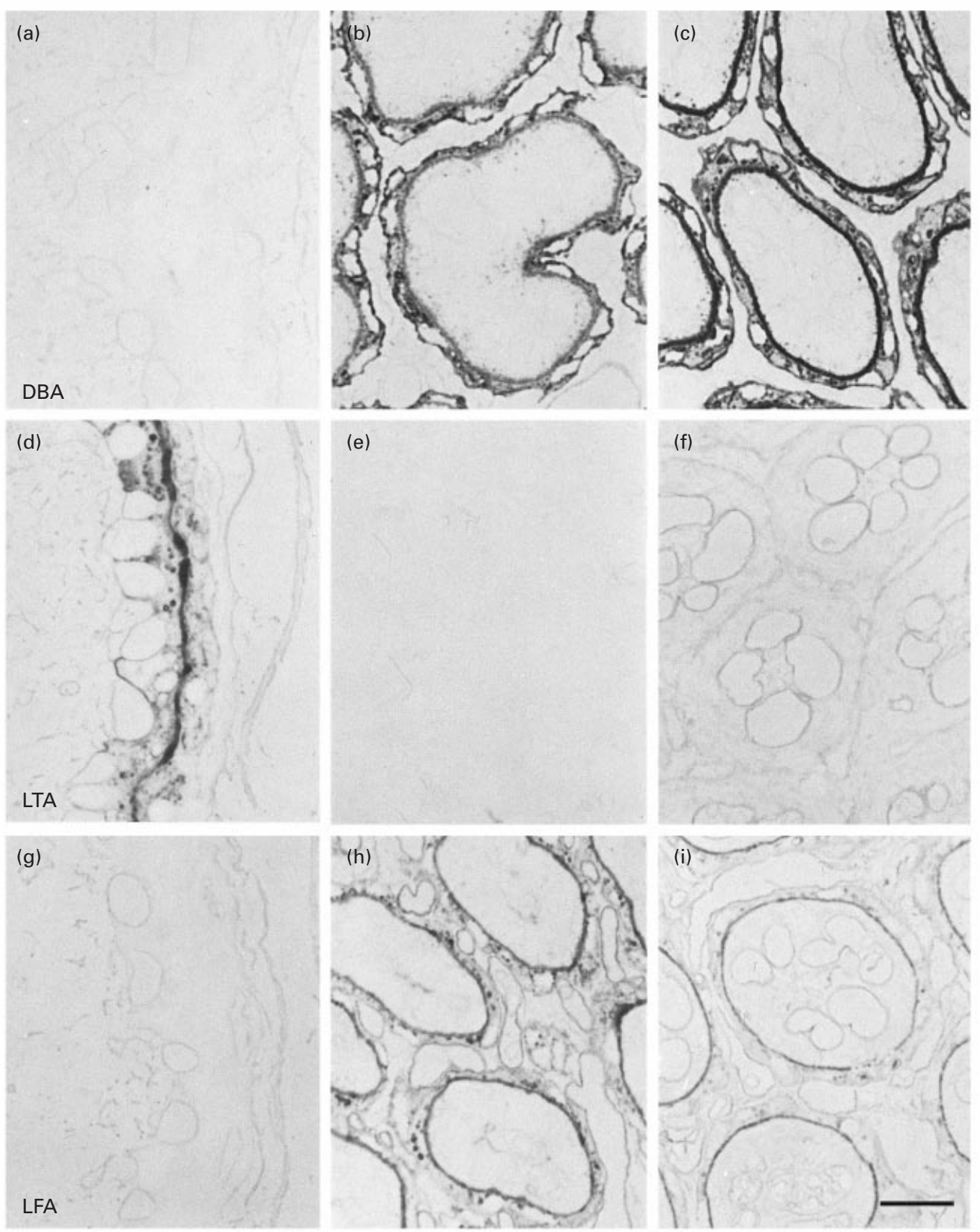

Fig. 2. (a-c) Dolichos biflorus agglutinin (DBA) shows absence of binding in the camel (a) and strong staining of horse (b) and donkey (c) maternal epithelia; these species also show staining of occasional granules in the trophoblast. (d-f) Tetragonolobus purpureus agglutinin (LTA) stains only the camel placenta (d); that of the horse (e) and donkey (f) do not bind. (g-i) Limax flavus agglutinin (LFA) does not bind to the camel placenta (g) but some granules are stained in the uterine epithelia of horse (h) and donkey (i). Scale bar represents $20 \mu \mathrm{m}$.

camel tissues are often quite different. This finding was especially evident in the microcotyledonary trophoblast, affecting particularly those glycans carrying terminal residues of fucose (LTA), the fucosylated structures GalNAc $\alpha 1,3$ (Fuc $\alpha 1,2)$ Gal $\beta 1,3 / 4$ GlcNAc $\beta 1-$ (DBA) and LFuc $\alpha 1,2 \mathrm{Gal} \beta 1,4 \mathrm{GlcNAc} \beta 1$ - (UEA-1), $N$-acetyl galactosamine (SBA), $\beta$-galactose (AHA, ECA) and non-bisected tri/ tetra-antennary complex $\mathrm{N}$-glycan (1-PHA). In the maternal uterine epithelium, the interspecific differences were less marked, being most prominent with DBA, LTA and LFA, which last interacts with sialic acid. In camels, there were also more bi-antennary and bisected structures. The presence of fucosylated termini is regulated by fucosyl transferases, and Sidhu and Kimber (1999) describe steroidally modulated alterations in the expression of the FUT1 $(\alpha(1-2)$ fucosyl transferase) gene, which is involved in the biosynthesis of 


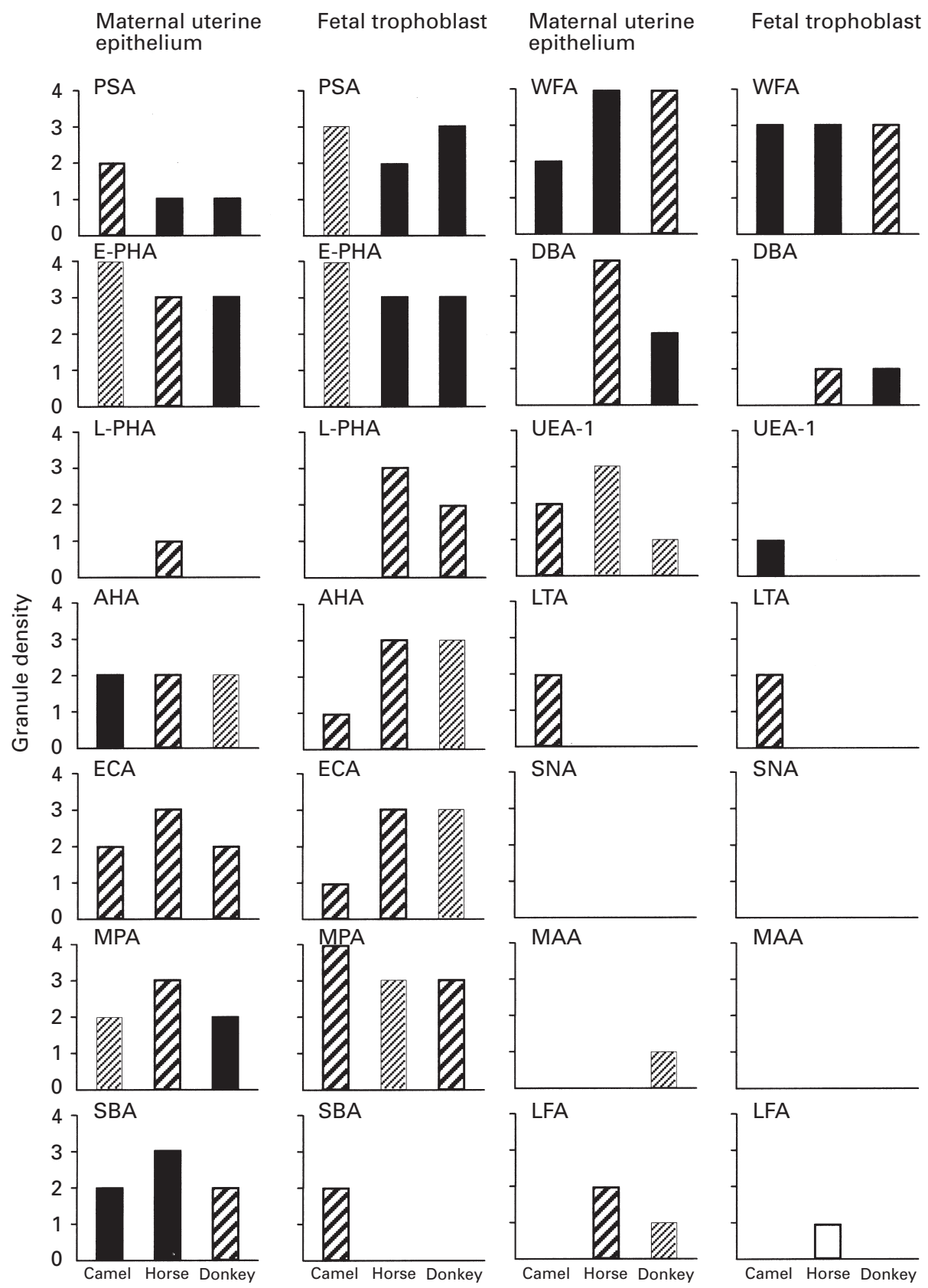

Fig. 3. Graphic representation of lectin binding to maternal uterine epithelium and fetal trophoblast in the camel, horse and donkey, with granule density ranging from 1 (sparse) to 4 (numerous) and staining intensity from weak to intense: $\square$, weak; $\mathbb{Z}$, moderate; $\mathbb{Z}$, strong; $\mathbf{\square}$, intense. PSA, Pisum sativum agglutinin; e-PHA, Phaseolus vulgaris erythroagglutinin; 1-PHA, Phaseolus vulgaris leukoagglutinin; AHA, Arachis hypogaea agglutinin; ECA, Erythrina cristagalli agglutinin; MPA, Maclura pomifera agglutinin; SBA, Glycine max agglutinin; WFA, Wisteria floribunda agglutinin; DBA, Dolichos biflorus agglutinin; UEA-1, Ulex europaeus-1 agglutinin; LTA, Tetragonolobus purpureus agglutinin; SNA, Sambucus nigra agglutinin; MAA, Maackia amurensis agglutinin; LFA, Limax flavus agglutinin.

$\alpha(1-2)$ fucosylated structures, in the mouse endometrium in early pregnancy. In the present study, it is evident that changes in the distribution of fucosyl residues are one of the most striking variations among species, as has also been shown in a comparison between human and baboon endometria (Jones et al., 1998).

Comparison with an earlier study on the pig placenta
(Jones et al., 1995) showed that the near-term pig trophoblast expressed glycans similar to those found in the camel, with PSA, 1-PHA, MPA, SBA, DBA, LTA and LFA showing similar patterns (e-PHA staining was not carried out), while the maternal epithelium was more like that of the horse and donkey, for example, in the binding of AHA, MPA, SBA, WFA, DBA, LTA and LFA. These findings follow the trend 
observed in the present study, with some conservation of glycans on the maternal side and more interspecies variation in the trophoblast. The pig placenta is epitheliochorial, diffuse and folded, resembling a thin, undulating membrane, in which maternal perpendicular folds create bulbous, villous-like structures on the fetal side (Dantzer, 1984), consistent with the fact that pigs are considered to be the most primitive living artiodactylae (Prothero, 1993).

Although it could be argued that the glycosylation patterns reported here are those seen near term, and so bear little relation to those expressed during early implantation, the previous study of placentation in horses showed that there are no major changes in the nature of the glycans present on either the uterine epithelium or the fetal trophoblast from 35 days to term, apart from a decrease in the amount of $\alpha 2,6$ - and $\alpha 2,3$ linked sialic acid (Jones et al., 1999). In the interdigitating microvillous membrane, there is a slight decrease in staining with some lectins after 200 days possibly caused by steric hindrance (Jones et al., 1999). In camels, there are variations in the degree of fucosylation (data not shown) but major changes with increasing gestational age are not found (C. J. P. Jones, unpublished). No early material was available from the donkey for comparison.

As glycans are so abundant at the two cell surfaces, they may be functionally significant in allowing initial attachment and subsequent implantation, and any aberration of this recognition system may be a cause of the failure of embryos to implant (Whyte and Allen, 1985). Despite the superficial similarities between the glycosylation of horse and donkey interhaemal barrier, in the case of the transfer of a pure donkey embryo to the uterus of a mare, there is a failure of interdigitation of allantochorionic villi with endometrial crypts, in contrast with conventional intraspecific equine pregnancy (Allen and Short, 1997). In about 70\% of donkeyin-horse pregnancies, implantation fails completely (Allen, 1982), apparently by a cell-mediated, cytotoxic response. In $30 \%$ of donkey-in-horse pregnancies, attachment and interdigitation occur eventually and development proceeds relatively normally until term. Fetal genotype and uterine microenvironment also exert marked, interacting influences on endometrial cup development and subsequent equine chorionic gonadotrophin (eCG) secretion rates in equids (Allen, 1982; Allen et al., 1987, 1993; Enders et al., 1996). Therefore, it appears that both genetic and immunological components influence the success of these pregnancies, and it seems likely that the glycans of the implanting trophoblast, partially controlled by the genotype of the embryo, may be contributory factors. Schlafke and Enders (1975) pointed out that the crucial, initial regulated step of the implantation process is the interaction of the trophoblast with the apical cell surfaces of uterine epithelial cells. This phenomenon has been described as a 'cell biological paradox' (Denker, 1990; Thie et al., 1996) as apical plasma membranes are generally non-adhesive, while basolateral domains normally express adhesion molecules. Attachment appears to be under steroid control (Carson et al., 1990; Aplin, 1997). A stage of apposition of the trophoblast to the uterus is followed by a progressive process of adhesion, as has been illustrated in the epitheliochorionic placenta of the camel (Skidmore et al., 1996; Abd-Elnaeim et al., 1999) and horse (Samuel et al., 1976;
Enders and Liu, 1991) with increasing interdigitation of apposing microvilli. As well as molecules such as cytokines, growth factors and integrins being implicated in cell-cell interactions of the placenta, it has been suggested that changes from a non-adhesive to adhesive state involve steroid-modulated alterations in the nature or distribution of glycoproteins (Schlafke and Enders, 1975; Denker, 1990; Cross et al., 1994; Wegner and Carson, 1994; Tabibzadeh and Babaknia, 1995; Thie et al., 1996; Aplin, 1997), with many different types of structure (glycans, lectins, cadherins, extracellular matrix, glycosyl transferases) acting as linking molecules.

Experiments with interspecific hybridization have also implicated the trophoblastic glycocalyx in successful implantation, whereas no close correlation has been found between the chromosome count or the duration of gestation and the ability of two species to hybridize (Gray, 1972). Fehilly et al. (1984) manipulated embryos in vitro so that the trophectoderm consisted of cells from the host, and this increased the probability of successful pregnancy. There are very few instances in nature of successful hybridization, but one of the more common man-made ones is the horse-donkey cross. The present findings indicate that if crossbred species, even when closely related, have different glycans on the surface membranes, then inappropriate or inadequate cell-cell interactions may occur resulting in a failure of implantation.

Jones et al. (1997a) compared the glycosylation patterns of different types of placenta from unrelated species and discussed the possible existence of species-specific 'glycotypes'. The purpose of such diversity, and the forces driving its development were unclear. Short (1976) suggested that natural selection must operate to minimize reproductive wastage and, therefore, there is probably evolutionary pressure to prevent the development of sterile hybrids, for example, mules and the hinnies resulting from donkey-horse crosses. This natural selection is best effected at an early stage, that is, by failure of implantation (or even fertilization), rather than by producing an offspring that reduces the reproductive potential of its mother by committing her to a long and fruitless gestation, and competing for limited resources to the detriment of fertile members of the herd.

This study has been supported by the Danish Veterinary and Agricultural Research Council to whom we are most grateful. The authors also thank the Wellcome Trust for the award of a Travel Grant to C. J. P. Jones. The authors would like to express their appreciation to J. Aplin (Department of Obstetrics and Gynaecology, University of Manchester) and D. Yalden (School of Biological Sciences, University of Manchester) for helpful discussion.

\section{References}

Abd-Elnaeim MM (1998) Some Morphological Studies on the Placenta of the Camel (Camelus dromedarius) PhD Thesis, Assiut University, Egypt

Abd-Elnaeim MM, Pfarrer C, Saber AS, Abou-Elmagd A, Jones CJP and Leiser R (1999) Feto-maternal attachment and anchorage in the early diffuse epitheliochorial placenta of the camel (Camelus dromedarius): light, transmission-, and scanning-electron microscopical study Cells Tissues Organs 164 141-154 
Allen WR (1982) Immunological aspects of the endometrial cup reaction and the effect of xenogeneic pregnancy in horses and donkeys Journal of Reproduction and Fertility Supplement 31 57-94

Allen WR and Short RV (1997) Interspecific and extraspecific pregnancies in equids: anything goes Journal of Heredity 88 384-392

Allen WR, Kydd JH, Boyle MS and Antczak DF (1987) Extraspecific donkeyin-horse pregnancy as a model of early fetal death Journal of Reproduction and Fertility Supplement 35 197-209

Allen WR, Skidmore JA, Stewart F and Antczak DF (1993) Effects of fetal genotype and uterine environment on placental development in equids Journal of Reproduction and Fertility 97 55-60

Aplin JD (1997) Adhesion molecules in implantation Reviews of Reproduction 2 84-93

Baker DA, Sugii S, Kabat EA, Ratcliffe RM, Hermentin P and Lemieux RU (1983) Immunochemical studies on the combining sites of Forssman hapten reactive hemagglutinins from Dolichos biflorus, Helix pomatia and Wistaria floribunda. Biochemistry 22 2741-2750

Bhattacharyya L, Haraldsson M and Brewer CF (1988) Precipitation of galactose-specific lectins by complex-type oligosaccharides and glycopeptides: studies with lectins from Ricinus communis (Agglutinin I), Erythrina indica, Erythrina arborescens, Abrus precatorius (Agglutinin), and Glycine max (Soybean) Biochemistry 27 1034-1041

Björkman, N (1970) An Atlas of Placental Fine Structure Baillière Tindall and Cassell, London

Carson DD, Wilson OF and Dutt A (1990) Glycoconjugate expression and interactions at the cell surface of mouse uterine epithelial cells and periimplantation-stage embryos Trophoblast Research 4 211-241

Churcher CS and Richardson MI (1978) Equidae. In Evolution of African Mammals pp 379-422 Eds VJ Maglio and HBS Cooke. Harvard University Press, Cambridge, Massachusetts and London

Cross JC, Werb Z and Fisher SJ (1994) Implantation and the placenta: key pieces of the development puzzle Science 266 1508-1518

Cummings RD and Kornfeld S (1982) Characterization of the structural determinants required for the high affinity interaction of asparagine-linked oligosaccharides with immobilized Phaseolus vulgaris leukoagglutinating and erythroagglutinating lectins Journal of Biological Chemistry 25711 230-11234

Dantzer V (1984) Scanning electron microscopy of exposed surfaces of the porcine placenta Acta Anatomica 118 96-106

De Boeck H, Loontiens FG, Lis H and Sharon N (1984) Binding of simple carbohydrates and some $\mathrm{N}$-acetyllactosamine-containing oligosaccharides to Erythrina cristagalli agglutinin as followed with a fluorescent indicator ligand Archives of Biochemistry and Biophysics 234 297-304

Debray H, Decout D, Strecker G, Spik G and Montreuil J (1981) Specificity of twelve lectins towards oligosaccharides and glycopeptides related to $\mathrm{N}$ glycosylproteins European Journal of Biochemistry 17 41-55

Denker H-W (1990) Trophoblast-endometrial interactions at embryo implantation: a cell biological paradox Trophoblast Research 4 3-29

Enders AC and Liu IKH (1991) Lodgement of the equine blastocyst in the uterus from fixation through endometrial cup formation Journal of Reproduction and Fertility Supplement 44 427-438

Enders AC, Meadows S, Stewart F and Allen WR (1996) Failure of endometrial cup development in the donkey-in-horse model of equine abortion Journal of Anatomy 188 575-589

Etzler ME and Kabat EA (1970) Purification and characterization of a lectin (plant hemagglutinin) with blood group A specificity from Dolichos biflorus. Biochemistry 9 869-877

Fehilly CB, Willadsen SM and Tucker EM (1984) Interspecific chimaerism between sheep and goat Nature 307 634-636

Gray AP (1972) Mammalian Hybrids Technical Communication Number 10 (Revised) of the Commonwealth Bureau of Animal Breeding and Genetics, Edinburgh

Green ED and Baenziger JU (1987) Oligosaccharide specificities of Phaseolus vulgaris leukoagglutinating and erythroagglutinating phytohemagglutinins. Interactions with $N$-glycanase-released oligosaccharides Journal of Biological Chemistry 26212 018-12029

Hammarström S, Hammarström ML, Sunblad G, Arnarp J and Lönngren J (1982) Mitogenic leukoagglutinin from Phaseolus vulgaris binds to a pentasaccharide unit in $N$-acetyllactosamine-type glycoprotein glycans Proceedings National Academy of Sciences USA 79 1611-1615

Hindsgaul O, Khare DP, Bachm M and Lemieux RU (1985) Molecular recognition III. The binding of the H-type 2 human blood group determinant by the lectin of Ulex europaeus. Canadian Journal of Chemistry 63 2653-2658
Iglesias JL, Lis H and Sharon N (1982) Purification and properties of a Dgalactose/ $N$-acetyl-D-galactosamine-specific lectin from Erythrina cristagalli. European Journal of Biochemistry 123 247-252

Jones CJP, Mosley SM, Jeffrey IJM and Stoddart RW (1987) Elimination of the non-specific binding of avidin to tissue sections Histochemical Journal 19 $264-268$

Jones CJP, Dantzer V and Stoddart RW (1995) Changes in glycan distribution within the porcine interhaemal barrier during gestation Cell and Tissue Research 279 551-564

Jones CJP, Dantzer V, Leiser R, Krebs C and Stoddart RW (1997a) Localisation of glycans in the placenta: a comparative study of epitheliochorial, endotheliochorial, and haemomonochorial placentation Microscopy Research and Technique 38 100-114

Jones CJP, Bäcklin B-M, Stoddart RW and Dantzer V (1997b) Environmental pollutants as aetiological agents in female reproductive pathology: placental glycan expression in normal and polychlorinated biphenyl (PCB)exposed mink (Mustela vison) Placenta 18 689-699

Jones CJP, Fazleabas AT, McGinlay PB and Aplin JD (1998) Cyclic modulation of epithelial glycosylation in human and baboon (Papio anubis) endometrium demonstrated by the binding of the agglutinin from Dolichos biflorus. Biology of Reproduction 58 20-27

Jones CJP, Wooding FBP, Dantzer V, Leiser R and Stoddart RW (1999) A lectin binding analysis of glycosylation patterns during development of the equine placenta Placenta 20 45-57

Knibbs RN, Goldstein IJ, Ratcliffe RM and Shibuya N (1991) Characterization of the carbohydrate binding specificity of the leukoagglutinating lectin from Maackia amurensis. Journal of Biological Chemistry 266 83-88

Knibbs RN, Osborne SE, Glick GD and Goldstein IJ (1993) Binding determinants of the sialic acid-specific lectin from the slug Limax flavus. Journal of Biological Chemistry 268 18524-18531

Kumar S and Hedges SB (1998) A molecular timescale for vertebrate evolution Nature 392 917-920

Leiser R and Kaufmann P (1994) Placental structure: in a comparative aspect Experimental and Clinical Endocrinology 102 122-134

Leiser R, Pfarrer C, Abd-Elnaeim M and Dantzer V (1998) Feto-maternal anchorage in epitheliochorial and endotheliochorial placental types studied by histology and microvascular corrosion casts Trophoblast Research 12 21-39

Lotan R and Sharon N (1978) Peanut (Arachis hypogaea) agglutinin Methods in Enzymology 50 361-367

Miller RL, Collawn JF and Fish WW (1982) Purification and macromolecular properties of a sialic acid-specific lectin from the slug Limax flavus. Journal of Biological Chemistry 257 7574-7580

Miyamoto MM, Kraus F, Laipis PJ, Tanhauser SM and Webb SD (1993) Mitochondrial DNA phyologenies with Artiodactyla. In Mammal Phylogeny - Placentals pp 268-281 Eds FS Szalay, MJ Novacek and MC McKenna. Springer-Verlag, New York, Berlin

Pereira MEA and Kabat EA (1974) Specificity of purified hemagglutinin (lectin) from Lotus tetragonolobus. Biochemistry 13 3184-3192

Pereira MEA, Kabat EA amd Sharon N (1974) Immunochemical studies on the specificity of Soybean agglutinin Carbohydrate Research 37 89-102

Prothero DR (1993) Ungulate phylogeny: molecular versus morphological evidence. In Mammal Phylogeny - Placentals pp 173-181 Eds FS Szalay, MJ Novacek and MC McKenna. Springer-Verlag, New York, Berlin

Samuel CA, Allen WR and Steven DH (1976) Studies on the equine placenta II. Ultrastructure of the placental barrier Journal of Reproduction and Fertility 48 257-264

Sarkar M, Wu AM and Kabat EA (1981) Immunochemical studies on the carbohydrate specificity of Maclura pomifera lectin Archives of Biochemistry and Biophysics 209 204-218

Schlafke S and Enders AC (1975) Cellular basis of interaction between trophoblast and uterus at implantation Biology of Reproduction 12 41-65

Shibuya N, Goldstein IJ, Broekaert WF, Nsimba-Lubaki M, Peeters B and Peumans WJ (1987) The elderberry (Sambucus nigra L) bark lectin recognizes the $\operatorname{Neu} 5 \mathrm{Ac}(\alpha 2,6) \mathrm{Gal} / \mathrm{GalNAc}$ sequence Journal of Biological Chemistry 262 1596-1601

Short RV (1976) The origin of species. In The Evolution of Reproduction pp 110-148 Eds CR Austin and RV Short. Cambridge University Press, Cambridge

Sidhu SS and Kimber SJ (1999) Hormonal control of H-type $\alpha(1-2)$ fucosyltransferase messenger ribonucleic acid in the mouse uterus Biology of Reproduction 60 147-157

Skidmore JA, Wooding FBP and Allen WR (1996) Implantation and early 
placentation in the one-humped camel (Camelus dromedarius) Placenta $\mathbf{1 7}$ 253-262

Steven DH (1982) Placentation in the mare Journal of Reproduction and Fertility Supplement 31 41-55

Sueyoshi S, Tsuji T and Osawa T (1988) Carbohydrate-binding specificities of five lectins that bind to O-glycosyl-linked carbohydrate chains. Quantitative analysis by frontal-affinity chromatography Carbohydrate Research 178 213-224

Sugii S and Kabat EA (1980) Immunochemical specificity of the combining site of Wisteria floribunda hemagglutinin Biochemistry 19 1192-1199

Tabibzadeh S and Babaknia A (1995) The signals and molecular pathways involved in implantation, a symbiotic interaction between blastocyst and endometrium involving adhesion and tissue invasion Human Reproduction $101579-1602$

Thie M, Fuchs P and Denker H-W (1996) Epithelial cell polarity and embryo implantation in mammals International Journal of Developmental Biology $\mathbf{4 0}$ 389-393

Trowbridge IS (1974) Isolation and chemical characterization of a mitogenic lectin from Pisum sativum. Journal of Biological Chemistry 249 6004-6012

Van Lennep EW (1961) The histology of the placenta of the one-humped camel
(Camelus dromedarius L) during the first half of pregnancy Acta morphologica neerlando - Scandinavica 4 180-193

Van Lennep EW (1963) The histology of the placenta of the one-humped camel (Camelus dromedarius L) during the second half of pregnancy Acta morphologica neerlando - Scandinavica 5373-379

Wang W-C and Cummings RD (1988) The immobilized leukoagglutinin from the seeds of Maackia amurensis binds with high affinity to complex-type Asnlinked oligosacharides containing terminal sialic acid-linked $\alpha 2,3$ to penultimate galactose residues Journal of Biological Chemistry 263 4576-4585

Wegner CC and Carson DD (1994) Cell adhesion processes in implantation Oxford Reviews of Reproductive Biology 16 87-137

Whyte A and Allen WR (1985) Equine endometrium at pre-implantation stages of pregnancy has specific glycosylated regions Placenta 6 537-542

Wooding FBP and Flint APF (1994) Placentation. In Marshall's Physiology of Reproduction Vol. 3, Pregnancy and Lactation, Ch. 4 pp 233-460 Ed GE Lamming. Chapman and Hall, London

Yamashita K, Hitoi A and Kobata A (1983) Structural determinants of Phaseolus vulgaris erythroagglutinating lectin for oligosaccharides Journal of Biological Chemistry 25814 753-14 755 